\title{
Avaliação da educação profissional: análise bibliométrica no âmbito da literatura científica
}

Maria da Conceição Lima Afonso

Remi Castioni

\section{Resumo}

Busca melhor entender como a questão da qualidade, por meio da avaliação, tem sido tratada na literatura científica, mais especificamente nas teses e dissertações defendidas no âmbito da temática de educação profissional. Considerando que a educação profissional desempenha um papel central na articulação do processo de formação profissional, faz-se cada vez mais necessário entender qual a qualidade da formação recebida pelo trabalhador brasileiro. Para atingir o objetivo proposto neste trabalho se classifica de forma ampla como pesquisa qualitativaexploratória, tendo como estratégia de levantamento de dados, a bibliometria e como método de análise, a análise de conteúdo. Como resultado, e tomando por base as pesquisas identificadas, é possível afirmar que pouco se conhece sobre como a qualidade da educação profissional tem sido desenvolvida e aplicada no Brasil. Sabe-se apenas que ocorre de forma descentralizada e por meio de diferentes mecanismos.

Palavras-chaves: Qualidade da Educação Profissional e Tecnológica. Educação Profissional e Tecnológica. Avaliação da Educação. 


\title{
Evaluation of professional education: bibliometric analysis within the scope of scientific literature
}

\author{
Maria da Conceição Lima Afonso \\ ConfiguraçõesRemi Castioni
}

Abstract

The article aims to better understand how quality, through the evaluation of learning, has been addressed in the scientific literature, more specifically in the theses and dissertations defended within the scope of Professional Education. Considering that Professional Education (PE) plays a central role in the articulation of the vocational training process, it becomes increasingly necessary to understand the quality of the training received by the Brazilian workers. Therefore, in order to reach the intended goal, this work is broadly classified as a qualitative-exploratory research, having bibliometry as a data collection strategy and content analysis as the method of analysis. As a result, and based on the research, it is possible to assert that little is known about how the quality of PE has been developed and applied in Brazil. It is only known that it occurs in a decentralized way and through different mechanisms.

Keywords: Quality of Professional and Technological Education. Professional and Technological Education. Evaluation of Education. 


\section{Introdução}

O conceito de qualidade, atrelado ao contexto educacional, tem histórico volumoso de diferentes interpretações ao ponto de alguns autores o considerarem subjetivo. $\mathrm{O}$ uso do termo qualidade no campo educacional é frequente e, talvez por ser frequente, torna-se de difícil, senão, impossível definição já que todos falam em qualidade supondo que sabem do que estão falando, é um "daqueles termos que são um resultado do triunfo da ambiguidade ou cuja textura é tão aberto e maleável, que acabará por se tornar rótulos, mantras ou enteléquias metafísicas (furtados de qualquer conteúdo político ou histórico), servindo consenso amplo e fácil” (MONTANÉ; BELTRÁN; TEODORO, 2017, p. 285). A grande questão é que o entendimento de qualidade passa por um crivo subjetivo, muitas vezes diretamente relacionado à percepção de um indivíduo ou de um grupo social, neste sentido, a qualidade “não existe em si e por si, mas sim é 'atribuída' a algo que tem propriedades 'físicas”, ou seja, refere-se a um "objeto de conhecimento que tem configuração própria; pode ser descrito e/ou até mesmo mensurável" (LUCKESI, 2014, p. 21). Considerando essa definição, o conceito de qualidade aplicada a educação pode estar vinculado a medição por meio do uso de instrumentos de avaliação da aprendizagem. Nesta perspectiva a avaliação educacional pode ser entendida como um instrumento que auxilia no processo de aferição da qualidade educacional.

No Brasil os principais avanços do uso de instrumentos que auxiliam nesse processo, ocorreram no âmbito da avaliação em larga escala, mais especificamente na educação básica (educação infantil, ensino fundamental e nível médio) e na educação superior. Exemplos dessas iniciativas são o Sistema Nacional de Avaliação da Educação Básica (SAEB), o Exame Nacional do Ensino Médio (ENEM) e o Sistema Nacional de Avaliação da Educação Superior (SINAES), por meio Exame Nacional de Desempenho de Estudantes (ENADE). Apesar dos avanços no contexto do desenvolvimento de sistemas que permitam mensurar a qualidade da educação básica e superior, atualmente o Brasil não conta com um sistema nacional de avaliação que possa aferir a qualidade da educação profissional oferecida.

A educação profissional desempenha um papel central na articulação do processo de formação técnica brasileiro. Por este motivo, nos últimos anos o país vem promovendo iniciativas importantes voltadas para educação profissional, como por exemplo, o Programa Nacional de Acesso ao Ensino Técnico e Emprego (PRONATEC) - criado em 2011, que busca expandir e interiorizar a oferta de formação profissional pelo país - e a recente reforma do ensino médio - por meio da Lei $n^{0}$ 13.415, de 16 de fevereiro de 2017 - que coloca a formação técnica e profissional como um possível caminho na formação dos estudantes. Diante desses esforços, o Brasil precisa entender melhor qual a qualidade da formação técnica hoje oferecida, tendo em vista que os mecanismos de medição dessa qualidade podem ser considerados 
indefinidos, seja conceitual ou metodologicamente.

É no âmbito desta temática que este trabalho foi desenvolvido, buscando melhor entender como a questão da qualidade tem sido tratada na literatura científica, mais especificamente nas teses e dissertações defendidas no âmbito da temática da educação profissional. Para atingir as expectativas deste trabalho os conteúdos estudados foram organizados em quatro partes principais: referencial teórico, que considera aspectos relacionados à educação profissional e avaliação da educação e da educação profissional no Brasil; aspectos metodológicos, que apresenta o passo-a-passo da pesquisa para atingir os resultados; os resultados obtidos, que mostra a aplicação da metodologia adotada com seus respectivos resultados; e as considerações finais.

\section{Educação Profissional no Brasil}

A educação profissional, do ponto de vista semântico, envolve dois aspectos principais e diretamente relacionados, que são a formação e o trabalho. Consequentemente, seu entendimento envolve múltiplas visões de diferentes atores sociais, que foram influenciadas por transformações econômicas, tecnológicas e sociais. Todas essas mudanças fomentaram alterações nos requisitos necessários para formação profissional, ampliando o "horizonte da profissionalização para a associação de conhecimento de saberes de várias áreas correlatas” (PEREIRA, 2016, p. 2). Ao longo do tempo, a educação profissional assume o papel de preparar para o exercício profissional de forma ampla, ou seja, com foco na formação geral para o trabalho e para a habilitação profissional. Para Castioni (1999, p. 24) a educação profissional, deve ser entendida "como uma construção social, cujos resultados não apenas se materializam no mercado de trabalho e em uma ocupação, mas ocorrem em outros espaços, como na família, no bairro, nas organizações sociais e políticas”. A educação profissional deve "preparar o sujeito para participar ativamente, colaborar, conviver e adaptar-se às demandas do mundo do trabalho" (PEREIRA, 2016, p. 3).

Do ponto de vista da legislação brasileira existente, a imprecisão do termo permanece e acompanha a história das legislações educacionais, promovendo uma constante oscilação terminológica (MORAES; ALBUQUERQUE, 2019). A promulgação da Lei de Diretrizes e Bases da Educação Brasileira (LDB) ${ }^{36}$ elevou a educação profissional a uma modalidade de ensino própria da educação, permitindo uma formação geral e ao mesmo tempo específica. A LDB de 1996, em seu art. 39, passou a considerar a Educação Profissional e Tecnológica (EPT) como a formação geral do educando, ou seja, a preparação geral para o trabalho e, facultativamente, a habilitação profissional, visando preparar o educando para o exercício de profissões (BRASIL,

\footnotetext{
${ }^{36}$ Lei no 9.394 , de 20 de dezembro de 1996.
} 
1996). Como consequência a EPT, integra-se aos diferentes níveis e modalidades de educação e às dimensões do trabalho, da ciência e da tecnologia, podendo ser organizados por eixos tecnológicos. No Brasil, a EPT abrange os seguintes cursos: I - de formação inicial e continuada ou qualificação profissional; II - de educação profissional técnica de nível médio; e III - de educação profissional tecnológica de graduação e pós-graduação. (BRASIL, 1996). Neste cenário, as dimensões da EPT tornam-se um desafio educacional, por serem amplas e complexas, não se restringindo a uma compreensão linear que apenas treina o indivíduo para o mercado de trabalho, nem a uma visão reducionista que apenas objetiva preparar o trabalhador para executar tarefas instrumentais (BRISTOT, 2012).

No Brasil, este desafio é representado por cerca 1,8 milhão de matrículas na EPT, um número pequeno tendo em vista que representa apenas 3,8\% do total de alunos matriculados na Educação Básica brasileira e 11,1\% do total de alunos do ensino médio regular que fazem educação profissional (integrado e concomitante) (INEP, 2018). Segundo dados do Censo da Educação Básica, as matrículas da EPT - considerando Formação Inicial e Continuada (FIC) e técnicas de nível médio - no período de 2008 (928 mil) a 2015 (1,8 milhão) dobraram, atingindo um crescimento de 107\%. Apesar do crescimento no período, impulsionado principalmente pelo PRONATEC, é importante destacar que entre 2015 e 2017 presenciamos uma queda de 4,5\% nas matrículas (INEP, 2018). Vale destacar que apesar dos avanços alcançados no que diz respeito ao número de matrículas, para um real avanço da EPT deve ser considerado também o viés da qualidade da educacional oferecida. Por este motivo, entender, em termos qualitativos, como os cursos, escolas e a formação tem sido ofertada é fundamental para garantir uma influência positiva para o trabalhador e o mercado de trabalho.

\section{Avaliação da Educação Profissional}

O processo de avaliação educacional em larga escala no Brasil ganhou forma a partir do último século, fazendo com que o país acumulasse grande experiência nesta área. Este acúmulo de experiência foi motivado, principalmente, pela carência de políticas públicas que buscassem a melhoria da qualidade da educação, tendo em vista que no país a expansão do sistema escolar ocorreu de forma pouco ordenada. Apenas com a promulgação da Constituição Federal de 1988 (CF 1988) é que a educação foi colocada como direito fundamental, sendo primordial garantir um padrão de qualidade - conforme pode ser observado no art. 206, inciso VII, o ensino será ministrado com base no princípio da "garantia de padrão de qualidade" (BRASIL, 1988). A CF 1988 tratou qualidade "como um princípio basilar do ensino a ser ministrado, ou seja, garantiu o direito à educação com 'padrão de qualidade' para todos”, sendo dever do Estado promovê-la, defini-la e aferi-la (CABRAL; DI GIORGI, 2012, p. 117).

No âmbito da qualidade da educação é fundamental o desenvolvimento de 
ferramentas e diagnósticos que permitam aferir a qualidade, sendo necessário o "estabelecimento de parâmetros de referência de aprendizagem e da indicação de padrões, insumos e processos eficazes que permitam avançar no rendimento escolar, mobilizando a opinião pública a favor da educação" (DOURADO; OLIVEIRA; SANTOS, 2007, p. 12). A avaliação no âmbito educacional pode ser entendida como um instrumento utilizado para auxiliar no processo de investigação e mensuração da qualidade da educação. No contexto educacional, a avaliação assume um papel dinâmico subsidiando diferentes atores (professores, coordenadores, diretores e gestores de modo geral) nas tomadas de decisões sejam elas pedagógicas ou não.

Neste sentido, como já mencionado, o Brasil conta hoje com quatro principais avaliações em larga escala, sendo: o SAEB, o ENEM e o SINAES, por meio ENADE. O SAEB, aplicado inicialmente em 1990, é considerado como a primeira iniciativa a realizar um diagnóstico da educação em escala nacional no Brasil. Foi desenvolvido com o objetivo de conhecer, em maior profundidade, a educação básica brasileira, fornecendo um indicativo sobre a qualidade do ensino ofertado, por meio da avaliação de fatores que podem interferir no desempenho do estudante (INEP, 2017). Aplicado com uma periodicidade de dois em dois anos, o SAEB passou por algumas reestruturações ao longo do tempo, como a incorporação da Teoria de Resposta ao Item (TRI). Já o ENEM se concentra no desempenho individual do aluno, seja ele escolar ou acadêmico, realizado ao final do ensino médio. Instituído em 1998, seus resultados podem: possibilitar a constituição de parâmetros para a autoavaliação; permitir a criação de referência nacional para o aperfeiçoamento dos currículos do Ensino Médio; ser utilizado como de acesso à Educação Superior (ES); permitir o acesso a programas governamentais de financiamento ou apoio ao estudante da Educação Superior; viabilizar o desenvolvimento de estudos e indicadores sobre a educação brasileira; dentre outros (INEP, 2015). O SINAES nasceu da necessidade de se estabelecer um sistema que unificasse os modelos existentes no Brasil e que tinham por objetivo avaliar partes da educação superior, como por exemplo, a avaliação dos cursos de pós-graduação realizado pela Coordenação de Aperfeiçoamento do Pessoal de Nível Superior (CAPES), iniciado na década 1970. O SINAES possui como finalidades, conforme estabelecido no $\operatorname{art.~}^{\mathrm{o}}, \S 1^{\mathrm{o}}$, da Lei $\mathrm{n}^{\mathrm{o}} 10.861 / 2004$,

$\S 1^{\mathrm{o}}$ O SINAES tem por finalidades a melhoria da qualidade da educação superior, a orientação da expansão da sua oferta, o aumento permanente da sua eficácia institucional e efetividade acadêmica e social e, especialmente, a promoção do aprofundamento dos compromissos e responsabilidades sociais das instituições de educação superior, por meio da valorização de sua missão pública, da promoção dos valores democráticos, do respeito à diferença e à diversidade, da afirmação da autonomia e da identidade institucional. (BRASIL, 2004).

No que diz respeito ao processo de avaliação do aluno, no âmbito do SINAES, é 
realizada por meio do ENADE com o objetivo de avaliar a qualidade dos cursos e das instituições de educação superior, tendo em vista que o desempenho insatisfatório dos alunos pode acarretar processo de supervisão pelo MEC (RABELO, 2013).

Dentre as avaliações brevemente apresentadas, observa-se que não existe de forma nacionalmente reconhecida e instituída um sistema de avaliação da educação profissional. Esta é uma tarefa que precisa ser enfrentada, visando estabelecer parâmetros e construir padrões de referência, que permitam a medição e a consequente análise dos resultados alcançados.

Assim como os demais sistemas de avaliação da qualidade da educação existentes no Brasil, o respaldo legal inicial para se pensar na avaliação da EPT veio por meio da CF 1988, por meio do princípio da garantia do padrão de sua qualidade. Além da CF 1988, a LDB de 1996, consolidou a definição de processos de avaliação, visando a busca pela qualidade. Outro respaldo legal existente é o Plano Nacional de Educação (PNE) que, por meio da Emenda Constitucional $n^{0} 59 / 2009$, passou a ser uma exigência constitucional com periodicidade decenal, sendo responsável por orientar a execução e o aprimoramento de políticas públicas no contexto educacional. O PNE 2014-2024, aprovado pela Lei ${ }^{0} 13.005$, de 25 de junho de 2014, traz dez diretrizes, entre elas a melhoria da qualidade da educação. São duas as METAS dispostas no PNE 2014-2024 com foco na EPT, a seguir:

- $\quad$ META 10 - Educação de Jovens e Adultos Oferecer, no mínimo, 25\% (vinte e cinco por cento) das matrículas de educação de jovens e adultos, nos ensinos fundamental e médio, na forma integrada à educação profissional.

- $\quad$ META 11 - Educação Profissional Técnica de Nível Médio

Triplicar as matrículas da Educação Profissional Técnica de nível médio, assegurando a qualidade da oferta e pelo menos $50 \%$ da expansão no segmento público.

As metas 10 e 11 do PNE 2014-2024, articulam-se aos esforços de ampliação da formação em EPT. Para este trabalho focaremos no entendimento da meta 11, considerando que em seu âmbito foram dispostas 14 Estratégias, dentre elas a Estratégia 11.8 que tem por foco a Avaliação. A Estratégia 11.8 é responsável por "institucionalizar sistema de avaliação da qualidade da educação profissional técnica de nível médio das redes escolares públicas e privadas”, que ainda não foi implementada (BRASIL, 2014, p. 72). A Estratégia 11.8, levanta uma questão fundamental, que é a de institucionalização de um sistema nacional de avaliação da educação profissional. Porém, apesar da questão encontrar-se mais do que justificada no Brasil, um planejamento consistente ainda não foi desenvolvido. Em 2014, a Secretaria de Educação Profissional e Tecnológica do Ministério da Educação (Setec/MEC), desenvolveu um documento que tinha por objetivo geral a elaboração de uma proposta de avaliação para a Educação Profissional, ou seja, o desenvolvimento do Sistema Nacional de Avaliação da Educação Profissional e Tecnológica (Sinaep), foi uma proposta coletiva, porém sua institucionalização não foi concretizada (DANTAS, 2014). Entender como esta temática vem 
sendo tratada na literatura, do ponto de vista dos dados bibliométricos, pode auxiliar no processo de desenvolvimento de um parâmetro metodológico forte, que identifique e aplique estratégias adequadas a institucionalização de uma avaliação da EPT.

\section{Aspectos Metodológicos}

Este trabalho se classifica de forma ampla como pesquisa qualitativa-exploratória, tendo como estratégia de levantamento de dados, a bibliometria e como método de análise, a análise de conteúdo. $\mathrm{O}$ uso da pesquisa qualitativa visa proporcionar uma compreensão melhor do contexto do problema. A escolha pela pesquisa exploratória justifica-se por se tratar do entendimento de um problema, buscando prover critérios para sua melhor compreensão (MALHOTRA, 2001). Os dados obtidos na coleta foram tratados por meio da análise de conteúdo, com adaptação das proposições oferecidas por Bardin (1977). Vale destacar que os materiais clássicos da análise de conteúdo são textos escritos que já foram usados para outras finalidades, mas que podem ser manipulados para fornecer as respostas às perguntas do pesquisador (BAUER, 2002).

A bibliometria foi adotada com o objetivo de medir e aferir a evolução da atividade científica sobre a produção de teses e dissertações que tratam da temática avaliação da educação profissional. O termo bibliometria foi utilizado por Pritchard (1969), visando quantificar os processos de comunicação escrita e consiste no estudo dos aspectos quantitativos da produção, disseminação e uso da informação registrada. Segundo McGrath (apud MACIAS-CHAPULA, 1998) ela se caracteriza por:

- $\quad$ objeto de estudo: livros, documentos, revistas, artigos, autores, usuários;

- variáveis: número de empréstimos (circulação) e de citações, frequência de citação de palavras, extensão de frases etc.; métodos ranking, frequência, distribuição; e

- $\quad$ objetivos: alocar recursos (tempo, dinheiro etc.).

Para atingir o objetivo esperado e responder aos questionamentos realizados o processo metodológico dividiu-se em três fases principais. A primeira diz respeito a coleta de dados, ou seja, ao levantamento das teses e dissertações. A segunda fase trata-se da análise dos dados, que pressupôs a leitura, entendimento e categorização das pesquisas recuperadas por temáticas. A última fase refere-se aos resultados obtidos, que buscou expor, em maior detalhamento, os aspectos identificados.

Para coleta dos dados recorreu-se ao Banco de Teses e Dissertações da CAPES, por disponibilizar resumos e textos integrais das teses e dissertações apresentadas no Brasil. Para isso foi adotado uma estratégia de busca e recuperação em duas etapas, com diferentes descritores, conforme figura 1. 
Figura 1 - Temáticas trabalhadas no âmbito da Educação Profissional: etapas

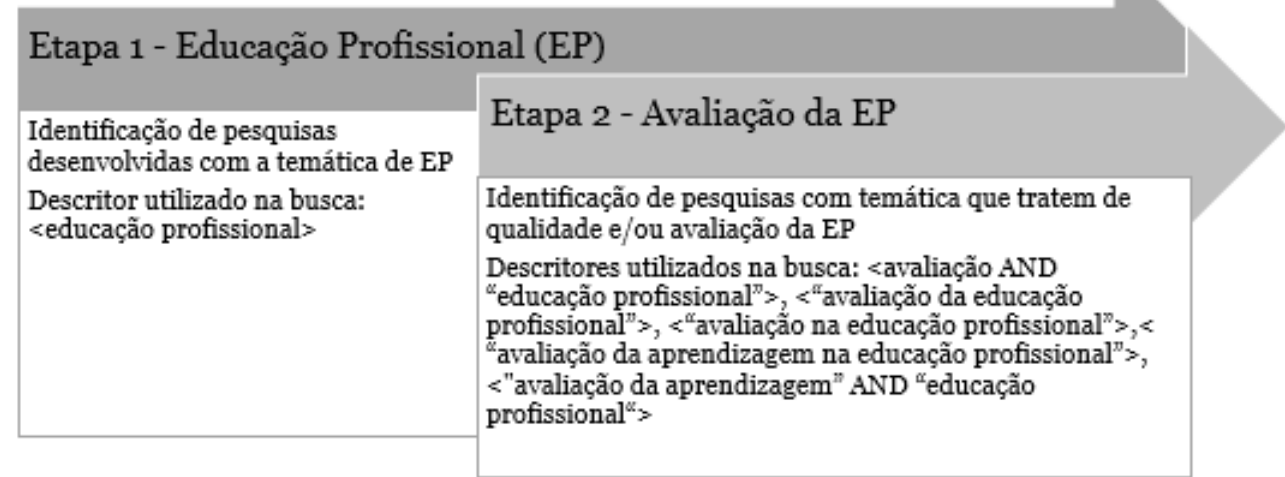

Fonte: Dos autores.

Tanto para a análise dos dados quanto para o fechamento dos resultados foi utilizado o Microsoft Office Excel. Durante a análise dos resultados foram consideradas: temáticas de pesquisas em Educação Profissional: identificação das principais temáticas estudadas no âmbito das teses e dissertações sobre a questão da educação profissional; avaliação da educação profissional: análise e categorização das teses e dissertações que tratavam sobre a questão da avaliação da educação profissional. Dentre a temáticas estudadas e discutidas buscou-se analisar como a questão da avaliação foi abordada e analisada. Para a categorização de assuntos foram analisados o título, o resumo e os descritores temáticos das teses e dissertações recuperadas, permitindo selecionar posteriormente as pesquisas de maior relevância para o desenvolvimento do trabalho.

\section{Resultados obtidos}

\section{Como a temática tem sido abordada na literatura científica}

Nos últimos anos, no âmbito das pesquisas recuperadas, observou-se que a temática de educação profissional tem sido alvo de grande atenção. Os últimos cinco anos (2012 a 2016) foram responsáveis por 56,3\% (1.748) das teses e dissertações concluídas, ao considerarmos uma série histórica de 22 anos (1994 a 2016). Esta concentração de pesquisas no período demonstram o crescimento do interesse em estudos e pesquisas desenvolvidos na temática de EPT. Para melhor clarificar essa afirmação e apresentando o resultado da estratégia metodológica adotada obteve-se a recuperação de 3.101 teses e dissertações que tinham como assunto principal a educação profissional.

Ao se buscar entender quais as principais tendências temáticas da EPT recuperadas, observou-se que a questão da educação profissional foi abordada por meio de diversos assuntos correlacionados (figura 2). No caso das teses e dissertações havia uma concentração maior nas categorias: Avaliação Educacional, Competências, Currículo, Docentes, Educação a 
Distância, Educação Básica (Ensino Fundamental, Ensino Médio), Educação Continuada, Educação de Jovens e Adultos (PROEJA), Educação Especial, Educação Superior, Financiamento da Educação, Mercado de Trabalho, Políticas Públicas, Qualidade, Questões de Gênero, Saúde, Tecnologia Educacional.

Figura 2 - Síntese das temáticas de pesquisas (teses, dissertações e artigos) em Educação Profissional

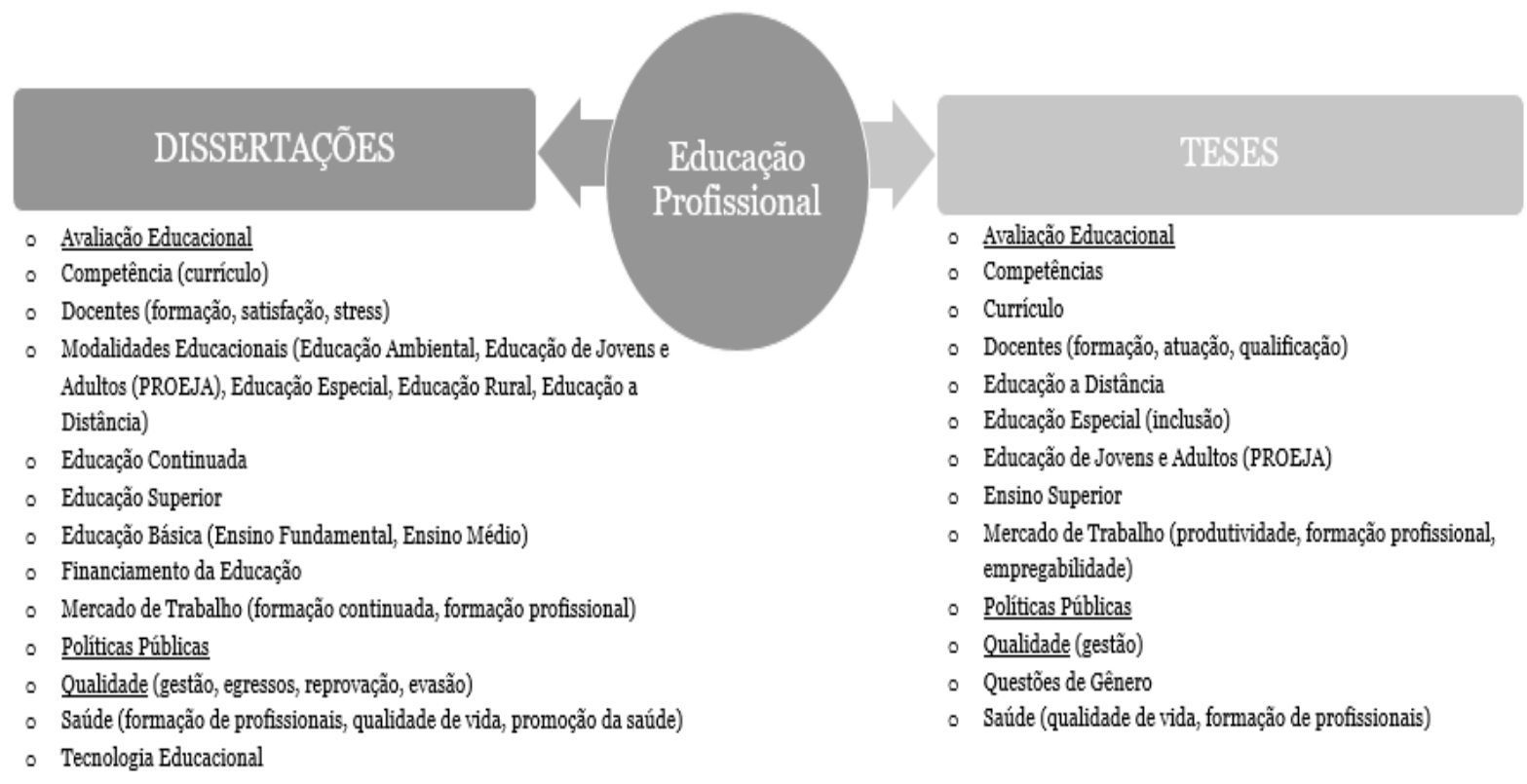

Fonte: Dos autores.

A Etapa 2 buscou entender, em maior profundidade, como a questão da avaliação da EPT foi tratada no âmbito dos trabalhos recuperados. Para isso, o processo foi dividido em três momentos:

- Identificação das pesquisas: responsável por identificar quais pesquisas apresentavam no título, no resumo ou nas palavras-chaves os parâmetros de busca delimitados na Etapa 2 (figura 1), ou seja, que tratavam da qualidade e/ou avaliação da EPT. Como resultado foram recuperadas 397 pesquisas (sendo 60 teses e 337 dissertações);

- Categorização dos conteúdos trabalhados: sintetiza os conteúdos, para um melhor entendimento dos principais agrupamentos temáticos realizados no âmbito da avaliação da EPT. O resultado dessa categorização foi apresentado no quadro 1. Ao todo foram identificadas 54 pesquisas (sendo 6 teses e 48 dissertações) que tratavam sobre o processo da avaliação da educação profissional seja propondo um modelo, uma análise conceitual e/ou um estudo de caso. 
Quadro 1 - Temáticas de pesquisas sobre a Avaliação da Educação Profissional.

\section{Macrotemas}

Avaliação da aprendizagem na Educação Profissional

Avaliação da aprendizagem na Educação Superior

\section{Subtemas}

Competências; Empresas; Estudos de Caso; Sistema Nacional de Avaliação da Educação Superior (SINAES); Docente (ponto de vista docente); Educação de Jovens e Adultos (EJA); Egressos; Evasão; Formação docente; Políticas públicas; Práticas pedagógicas.

Educação profissional (tecnólogo); Cursos Superiores de Tecnologia; Políticas públicas.

Educação profissional; Avaliação de cursos; Ensino Médio Integrado;

Avaliação de programas educativos e cursos Estudos de caso; Plano Nacional de Qualificação do Trabalhador (PLANFOR); PROEJA; PRONATEC; Programa Jovem Aprendiz; Relações públicas; Saúde (cursos de educação profissional em saúde); e Cursos Tecnólogos.

Avaliação da aprendizagem na Educação Básica

Ensino Médio Integrado; Ensino Médio Técnico. Avaliação em larga escala Comparativo e/ou análise internacional; ENEM; Censo da Educação

Avaliação institucional

Estudos de caso (Institutos Federais, SENAI, SENAC, entre outros); Políticas públicas; Desempenho docente.

Fonte: Dos autores.

Nas pesquisas sintetizadas no quadro 1, é possível observar que apesar da avaliação da EPT ter sido estudada sob diferentes pontos de vista - como por exemplo, das políticas públicas e dos indicadores - o aspecto avaliação foi o elemento principal, ou seja, todos os exemplos apresentados analisaram aspectos do processo de avaliação da aprendizagem. Estes elementos foram aplicados, em grande maioria, em uma única instituição ou partiram do ponto de vista de uma metodologia específica ou ainda de uma única modalidade da EPT (ensino médio integrado, por exemplo). Essa diversidade temática contou com a contribuição de uma multiplicidade de áreas/programas de doutorado e mestrado, sendo que a área de Educação apresentou o maior número de contribuições o equivalente a 41\% (22), seguida da área de Engenharia, com 17\% (9), e Administração, com 11\% (6) (tabela 1). Apesar da predominância no âmbito da Educação, a ocorrência da temática em outras áreas pode evidenciar que a preocupação com a qualidade da educação profissional ofertada vai além do que é refletido pela área educacional. 
Tabela 1 - Distribuição das pesquisas recuperadas por área

\begin{tabular}{|c|c|c|}
\hline Área & $\begin{array}{c}\text { otal de }^{\mathrm{T}} \\
\text { pesquisas }\end{array}$ & \\
\hline Educação & 2 & $1 \%$ \\
\hline Engenharia & 9 & $7 \%$ \\
\hline Administração & 6 & $1 \%$ \\
\hline Gestão de Políticas Públicas & 2 & $\%$ \\
\hline Psicologia & 2 & $\%$ \\
\hline Tecnologia & 2 & $\%$ \\
\hline Avaliação de Políticas Públicas & 1 & $\%$ \\
\hline Ciências Ambientais & 1 & $\%$ \\
\hline Desenvolvimento Regional & 1 & $\%$ \\
\hline Estudos Populacionais e Pesquisas Sociais & 1 & $\%$ \\
\hline Gestão Organizacional & 1 & $\%$ \\
\hline Políticas Sociais e Cidadania & 1 & $\%$ \\
\hline Qualidade & 1 & $\%$ \\
\hline Química & 1 & $\%$ \\
\hline Saúde & 1 & $\%$ \\
\hline Sistemas de Gestão & 1 & $\%$ \\
\hline Sociologia & 1 & $\%$ \\
\hline Total & 5 & $00 \%$ \\
\hline
\end{tabular}

Considerando-se que foram localizadas pesquisas desde 1991, a distribuição temporal desses resultados mostra que o período de 2002 a 2017 foi responsável por 87\% (47) das pesquisas recuperadas no âmbito da temática da avaliação na EPT (gráfico 1). Os últimos cinco anos, respondem por 48\% (26) das pesquisas, evidenciando um crescente interesse sobre a temática. Sob este ponto de vista, apesar deste período ter sido responsável por $48 \%$ dos trabalhos publicados que consideravam a avaliação da educação profissional, estas representaram apenas $13,6 \%$ do total das pesquisas desenvolvidas no âmbito desta temática. Se formos considerar todas as pesquisas desenvolvidas no âmbito da EPT esse número cai para apenas $1,7 \%$. Um número pequeno se considerarmos a relevância e a carência de discussões sobre a tema. 


\section{Gráfico 1 - Distribuição temporal das pesquisas recuperadas}

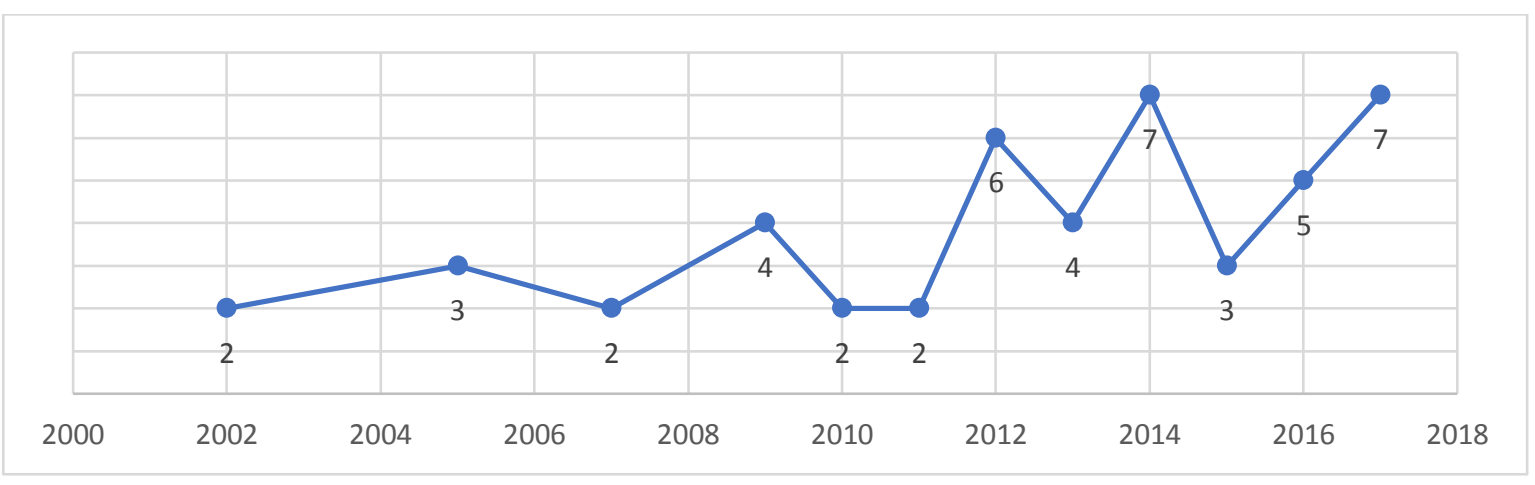

Fonte: Dos autores.

Se analisarmos sob o ponto de vista das universidades que mais pesquisam sobre a avaliação da EPT, observa-se que 10 universidades concentraram mais de 50\% (28) das teses e dissertações (tabela 1). Vale destacar que a grande maioria dos trabalhos são de mestrado (88,9\%), isso é refletido também nas universidades, por exemplo, a Universidade Federal do Ceará que apresentou o maior número de trabalhos teve apenas uma tese que abordava a temática. Talvez a ausência de uma avaliação sistematizada da EPT a nível Federal, não tenha fomentado no âmbito das universidades uma investigação ainda mais complexa e aprofundada da temática que resultaria no aumento no número de teses, em detrimento das atuais 6 teses defendidas desde 1991.

Tabela 2 - Universidades com maior número de teses e dissertação, por nível

\begin{tabular}{|c|c|c|c|c|}
\hline Universidade & Doutorado & $\begin{array}{l}\text { Nível } \\
\text { Mestrado }\end{array}$ & $\begin{array}{c}\text { Total de } \\
\text { pesquisas }\end{array}$ & $\begin{array}{c}\text { \% em } \\
\text { relação ao } \\
\text { total }\end{array}$ \\
\hline Universidade Federal do Ceará & 1 & 5 & 6 & $11 \%$ \\
\hline Universidade de Brasília & - & 4 & 4 & $7 \%$ \\
\hline $\begin{array}{l}\text { Universidade Federal da Bahia } \\
\text { Universidade Federal do Rio Grande do } \\
\text { Norte }\end{array}$ & 1 & 3 & 3 & $\begin{array}{l}6 \% \\
6 \%\end{array}$ \\
\hline Universidade Federal Fluminense & - & 2 & 2 & $4 \%$ \\
\hline Universidade Federal do Amazonas & - & 2 & 2 & $4 \%$ \\
\hline Universidade do Estado da Bahia & - & 2 & 2 & $4 \%$ \\
\hline Universidade do Vale do Rio dos Sinos & 1 & 1 & 2 & $4 \%$ \\
\hline $\begin{array}{l}\text { Universidade Estadual de Campinas } \\
\text { Centro Estadual de Educação } \\
\text { Tecnológica Paula Souza }\end{array}$ & $\begin{array}{l}1 \\
-\end{array}$ & $\begin{array}{l}1 \\
2\end{array}$ & $\begin{array}{l}2 \\
2\end{array}$ & $\begin{array}{l}4 \% \\
4 \%\end{array}$ \\
\hline
\end{tabular}

No âmbito dos trabalhos recuperados, observou-se apenas tentativas isoladas que buscaram instituir um modelo ou metodologia de avaliação. Exemplo disto são as pesquisas desenvolvidas por Cassiano (2017), Dorneles (2011), Galvão (2017), Genesini (1998), Guidi (2016), Silva (2002) e Souza (2016), todas estas pesquisas buscaram respostas para o processo 
de avaliação da EPT, por meio da definição de indicadores e/ou metodologias. O trabalho de Thomaz (2013), por exemplo, utilizou como fonte de entendimento quanto ao desempenho e a qualidade da EPT por meio dos Relatórios de Gestão anuais (2007 a 2011), enviados ao TCU, pelos Institutos Federais. Thomaz (2013) analisa os indicadores por região, por crescimento de unidades de ensino e por origem das instituições. Já a pesquisa realizada por Matos (2012), partiu dos dados do Censo da Educação Básica e do Exame Nacional do Ensino Médio (ENEM) para analisar a qualidade do ensino médio profissional no Brasil.

\section{Considerações finais}

O trabalho proposto teve como objetivo principal entender como a questão da qualidade, por meio da avaliação da aprendizagem, tem sido tratada na literatura científica, mais especificamente nas teses e dissertações defendidas no âmbito da temática de Educação Profissional. Como resultado observou-se, quatro aspectos principais: a diversidade temática; o número pequeno de pesquisas recuperadas; um aumento da produção científica nos últimos cinco anos; e uma maior produção de dissertações em comparação com o número de teses.

A diversidade temática levou em consideração o fato da avaliação da EPT ter sido estudada sob diferentes pontos de vista, como por exemplo, competências, Sistema Nacional de Avaliação da Educação Superior (SINAES), Docente (ponto de vista docente), EJA, Egressos, dentre outros. Essa diversidade temática contou com a contribuição de uma multiplicidade de áreas/programas de doutorado e mestrado, sendo que a área de Educação foi a que apresentou o maior número de contribuições no que diz respeito às teses e dissertações desenvolvidas. Esta questão era algo esperado tendo em vista que a EPT é uma modalidade caracterizada pela transversalidade de atuação, podendo ser aplicada em diferentes níveis de ensino.

Além disso, apresentou um pequeno número de pesquisas recuperadas, isto se considerados o universo de documentos que tratam a questão da EPT e a relevância social da temática. Nesta questão identificou-se apenas tentativas isoladas que buscavam instituir um modelo ou metodologia de avaliação aplicados, em grande maioria, a uma única instituição e/ou que partiram do ponto de vista de uma metodologia específica ou ainda de uma única modalidade da EPT (ensino médio integrado, por exemplo). Apesar disso observou-se um crescimento no número de trabalhos defendidos nos últimos cinco anos, o que pode demonstrar um maior reconhecimento por parte da comunidade acadêmica, mesmo que ainda com maior presença do número de dissertações, da importância em discutir e aprofundar a questão.

Apesar da necessidade e importância da realização de uma avaliação da EPT no Brasil, sabe-se apenas que ocorre de forma descentralizada e por meio de diferentes mecanismos. Isto 
demonstra a carência de um melhor entendimento do tema no meio acadêmico, visando fomentar mais discussões que posteriormente possam corroborar para o desenvolvimento sistemático de uma política de avaliação da educação profissional.

\section{Referências}

BARDIN, Laurence. Análise de conteúdo. Lisboa: Edições 70, 1977.

BAUER, M. W. Análise de conteúdo clássica: uma revisão. BAUER, M. W.; GASKELL, G. Pesquisa qualitativa com texto, imagem e som: um manual prático. 13. ed. Rio de Janeiro: Vozes, p. 189-217. 2002.

BRASIL. Constituição (1988). Constituição da República Federativa do Brasil. Brasília, DF: Senado Federal: Centro Gráfico, 1988. 292 p.

BRASIL. Lei $\mathrm{n}^{0}$ 10.861, de 14 de abril de 2004. Institui o Sistema Nacional de Avaliação da Educação Superior - SINAES e dá outras providências. DOU, 15 abr. 2004a. Disponível em: <https://www.planalto.gov.br/ccivil_03/_Ato20042006/2004/Lei/L10.861.htm>. Acesso em: jul. 2018.

BRASIL. Lei no 13.005 de 25 de junho de 2014. Aprova o Plano Nacional de Educação - PNE e dá outras providências. DOU, 26 jun. 2014. Disponível em: <https://www.planalto.gov.br/ccivil_03/_ato2011-2014/2014/lei/l13005.htm>. Acesso em: nov. 2016.

BRASIL. Lei no 9.394, de 20 de dezembro de 1996. Estabelece as diretrizes e bases da educação nacional. DOU, 23 dez. 1996. Disponível em: <https://www.planalto.gov.br/ccivil_03/Leis/L9394.htm>. Acesso em: set. 2017.

BRISTOT, V. M. Desenvolvimento de um modelo de gestão educacional de avaliação aplicado no ensino médio/técnico-profissionalizante voltado a melhoria da qualidade na indústria de conformação cerâmica. 2012. Tese (Doutorado em Engenharia) - Universidade Federal do Rio Grande do Sul. Escola de Engenharia. Programa de Pós-Graduação em Engenharia de Minas, Metalúrgica e de Materiais, Porto Alegre, 2012. Disponível em: <https://lume.ufrgs.br/handle/10183/62043>. Acesso em: jul. 2018.

CABRAL, K. M.; DI GIORGI, C. A. G. O direito à qualidade da Educação Básica no Brasil: uma análise da legislação pertinente e das definições pedagógicas necessárias para uma demanda judicial. Educação, Porto Alegre, v. 35, n. 1, p. 116-128, jan./abr, 2012. Disponível em: <http://revistaseletronicas.pucrs.br/ojs/index.php/faced/article/viewFile/8412/75 47>. Acesso em: jul. 2018.

CASSIANO, Elaine Borges M. Proposição Metodológica de Avaliação da Eficiência na ISSN 2526-2882 
Educação Profissional e Tecnológica. 2017. Tese (Doutorado em Ciências Ambientais e Sustentabilidade Agropecuária) - Universidade Católica Dom Bosco, Campo Grande, 2017.

CASTIONI, R. Avaliação de políticas públicas: modelos e usos da avaliação de impacto em programas de formação profissional. In: Encontro Nacional de Estudos do Trabalho, 6., 1999. Anais... Belo Horizonte: UFMG, 1999.

DANTAS, Anna C. C. (Coord.). Avaliação da Educação Profissional e Tecnológica: proposta para o Sistema Nacional de Avaliação da Educação Profissional Tecnológica: Documento base. Brasília: MEC, 2014. Disponível em: <http://www2.ifam.edu.br/IV-enped/documentos/apresentacoes/ooooo26164sinaep_documento-base.pdf $>$. Acesso em: jun. 2018.

DORNELES, Rachel Pereira. Avaliação da educação profissional: um estudo sobre indicadores educacionais específicos. 2011. 139 f. Dissertação (Mestrado em Educação) - Universidade de Brasília, Brasília, 2011. Disponível em: <https://bit.ly/2MZpkaR>. Acesso em: jun. 2018.

DOURADO, L. F.; OLIVEIRA, J. F.; SANTOS, C. A. A qualidade da educação: conceitos e definições. Série Documental: Textos para Discussão, Brasília, DF, v. 24, n. 22, p. 5-34, 2007.

GALVÃO, Laila. Avaliação da qualidade dos serviços educacionais na perspectiva da comunidade acadêmica de um Instituto Federal: o emprego da escala Servqual. 2017. 105 f. Dissertação (Mestrado em Gestão Organizacional) Universidade Federal de Goiás, Catalão, 2017. Disponível em: <https://bit.ly/2xoiKpD>. Acesso em: jun. 2018.

GENESINI, Teresa A. Gomes. Avaliação e qualidade na Educação profissional. 1998. 164f. Dissertação (mestrado) - Universidade Estadual de Campinas, Instituto de Matemática Estatística e Computação Cientifica, Campinas, SP. Disponível em: <https://bit.ly/2MkP5gJ>. Acesso em: jul. 2018.

GUIDI, Renata Lissa Soares da Silva. Relações institucionais e educação profissional e tecnológica: uma análise da eficiência institucional. 2016. 148f. Tese (Doutorado em Administração) - Centro de Ciências Sociais Aplicadas, Universidade Federal do Rio Grande do Norte, Natal, 2016. Disponível em: < https://bit.ly/2CDbGoQ >. Acesso em: jul. 2018.

INEP. Censo da Educação Básica, 2017. Brasília: INEP, 2018.

INEP. SAEB. 2017. Disponível em: <http://portal.inep.gov.br/educacao-basica/saeb>. Acesso em: jul. 2018.

INEP. ENEM. 2015. Disponível em: <http://portal.inep.gov.br/web/guest/enem>. Acesso ISSN 2526-2882 
em: jul. 2018.

LUCKESI, C. C. Sobre notas escolares: distorções e possibilidades. São Paulo: Cortez, 2014. MACIAS-CHAPULA, Cesar A. O papel da informetria e da cienciometria e sua perspectiva nacional e internacional. Ci. Inf., Brasília , v. 27, n. 2, p. nd, 1998 . Disponível

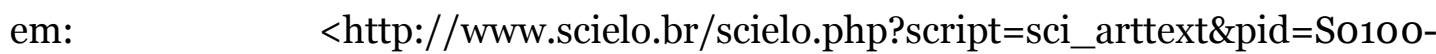
$19651998000200005 \& \operatorname{lng}=e n \& n r m=$ iso $>$. Acesso em: dez. 2016.

MATOS, Eduardo Guedes de. Uma análise da educação profissional de nível médio no Brasil. 2012. 109 f. Dissertação (Mestrado em Estudos Populacionais e Pesquisas Sociais da Escola Nacional de Ciências Estatísticas) - Instituto Brasileiro de Geografia e Estatísticas, Escola Nacional de Ciências Estatísticas, Rio de Janeiro, 2012. Disponível em: <https://bit.ly/2x3upUv>. Acesso em: jun. 2018.

MONTANÉ, A.; BELTRÁN, J.; TEODORO, A. La medida de la calidad educativa: acerca de los rankings universitarios. Revista de la Asociación de Sociología de la Educación (RASE), v. 10, n. 2, 2017. Disponível em: <https://bit.ly/2oW7NBP>. Acesso em: set. 2018.

PEREIRA, C. P. da S. Parâmetros psicométricos de uma escala de avaliação de estratégias de aprendizagem para o ensino profissionalizante. Dissertação (Mestrado) - Programa de Pós-Graduação Stricto Sensu em Psicologia da Universidade São Francisco, Itatiba, 2016.

RABELO, M. Avaliação educacional: fundamentos, metodologia e aplicações no contexto brasileiro. Rio de Janeiro: SBM, 2013.

SILVA, Adiel C. D. Proposta de gestão da qualidade para educação profissional de nível técnico. 2002. Dissertação (Mestrado em Ciências do Ambiente e Sustentabilidade na Amazônia) - Universidade Federal do Amazonas, Manaus, 2002.

SOUZA, D. S. de. Ferramentas de monitoramento e avaliação: uma aplicação no Instituto Federal de Brasília. 2016. 107 f., il. Dissertação (Mestrado Profissional em Gestão Pública) - Universidade de Brasília, Brasília, 2016. Disponível em: <https://bit.ly/2Qn8Jfh>. Acesso em: jul. 2018.

THOMAZ, Solange Marlene. Avaliação do impacto do plano de expansão da rede federal na qualidade dos institutos federais de educação segundo indicadores de desempenho. 2013. 109 f. Dissertação (Mestrado em Estratégia; Qualidade; Gestão Ambiental; Gestão da Produção e Operações) - Universidade Federal do Rio Grande do Norte, Natal, 2013. Disponível em: $<$ https://bit.ly/2x2vY5X>. Acesso em: jun. 2018. 


\section{Biografia Resumida}

Maria da Conceição Lima Afonso: Doutoranda em Educação pela Faculdade de Educação (FE) da Universidade de Brasília (UNB). Mestre em Ciência da Informação pela Universidade de Brasília (UnB). Atua como Analista de Desenvolvimento Industrial no Serviço Nacional de Aprendizagem (SENAI/DN). Atuou como Professora Substituta na Faculdade de Ciência da Informação (FCI) da Universidade de Brasília (UnB).

Link do lattes: http://lattes.cnpq.br/6109685689341426

Contato: mconceicaoafonso@gmail.com

Remi Castioni: Doutor em Educação pela Universidade Estadual de Campinas (2002). Realizou pós-doutorado na Universitat de Barcelona, junto ao Institut de Recerca en Educació (2017/18). Atualmente é professor-pesquisador da Universidade de Brasília, classe Associado, atuando na Faculdade de Educação e membro permanente dos Programas de Pós-Graduação em Educação (acadêmico e profissional). Atua no tema da transição entre educação e trabalho, com ênfase em qualificação profissional, certificação profissional e ensino médio e ainda nos seguintes temas: educação, políticas comparadas de educação profissional, indústria 4.o, sistema nacional de emprego, desenvolvimento regional e sistema nacional de inovação. Foi membro do Fórum Nacional de Educação - FNE e do Fórum Distrital de Educação - FDE. Foi diretor da Associação Brasileira de Estudos do Trabalho - ABET. Foi Membro do Comitê Nacional de Políticas de Educação Profissional e Tecnológica CONPEP, da SETEC/MEC. Foi membro do Conselho Diretor do Fundo PIS-PASEP. Foi diretor da Federação de Sindicatos de Professores e Professoras de Instituição Federais de Ensino Superior e de Ensino Básico Técnico e Tecnológico e diretor por dois mandados da Associação dos Docentes da Universidade de Brasília - UnB. Foi presidente da Associação dos Pesquisadores e Estudantes Brasileiros na Catalunha - APEC É membro do conselho editorial da Revista Com Censo da SEEDF e do corpo editorial da Editora CulturaTrix. É membro da diretoria da Sociedade Brasileira de Educação Comparada 
- SBEC.

Link do lattes: http://lattes.cnpq.br/9042288666288034

e-mail: kotipora@gmail.com 